\title{
Radiographic abnormalities and mortality in subjects with exposure to crocidolite
}

\author{
Nicholas H de Klerk, A William Musk, William O C M Cookson, John J Glancy, \\ Michael S T Hobbs
}

Abstract

Plain chest radiographs from a one in six random sample of the workforce of the asbestos industry at Wittenoom, Western Australia between 1943 and 1966 have been classified for degree of profusion and pleural thickening by two independent observers according to the 1980 UICC-ILO Classification of Radiographs for the pneumoconioses to clarify the effect of degree of radiological abnormality on survival. A total of 1106 subjects were selected. Each subject's age, cumulative exposure to crocidolite, and time since first exposure were determined from employment records, the results of a survey of airborne concentrations of fibres $>5 \mu$ in length conducted in 1966, and an exposure rating by an industrial hygienist and an ex-manager of the mine and mill at Wittenoom. By the end of 1986193 subjects had died. Conditional logistic regression was used to model the relative risk of death in five separate case-control analyses in which the outcomes were deaths from: (1) all causes, (2) malignant mesothelioma, (3) lung cancer, (4) asbestosis, and (5) other causes excluding cancer and asbestosis. Up to 20 controls per case were randomly chosen from all men of the same age who were not known to have died before the date of death of the index case. After adjustment for exposure and time since first exposure, there were significant and independent effects of radiographic profusion and pleural thickening on all cause mortality. The effect of profusion was largely a result of the effect on mortality from malignant

Department of Respiratory Medicine

A W Musk, W O C M Cookson

Department of Diagnostic Radiology, Sir Charles

Gairdner Hospital, Nedlands, Western Australia

J J Glancy

Department of Public Health, University of Western

Australia

N H de Klerk, M S T Hobbs mesothelioma and asbestosis but not lung cancer. The effect of pleural thickening was greatest on mortality from other causes, mainly ischaemic heart disease. This study has shown that degree of radiographic abnormality has an independent effect on mortality from malignant mesothelioma, asbestosis, and all causes even after allowing for the effects of age, degree of exposure, and time since first exposure.

\section{(British Fournal of Industrial Medicine 1993;50:902-906)}

Subjects with exposure to asbestos with or without pneumoconiosis have been shown to be subject to excessive mortality from malignant and non-malignant diseases of the respiratory and gastrointestinal tracts. ${ }^{1-3}$ Incidence and mortality for some of these diseases have been related to the degree of exposure and the time since exposure to asbestos. ${ }^{4-6}$

A previous study of crocidolite workers from Wittenoom Gorge in Western Australia who had applied for compensation for asbestosis showed that mortality was also related to the profusion of radiographic abnormalities on the plain chest radiograph $^{7}$ and there have been similar findings elsewhere in workers exposed to chrysotile. ${ }^{8}$ More recently some studies have suggested that asbestosis is responsible for the excess of cases of lung cancer in asbestos workers and have shown significant effects of exposure to asbestos on lung cancer only in those with asbestosis diagnosed either radiographically9 ${ }^{9}$ or histopathologically. ${ }^{10}$

The study among Wittenoom workers applying for compensation ${ }^{7}$ also showed an effect of amount of exposure on severity of radiographic profusion but survival in this group of workers was not significantly related to cumulative exposure to asbestos. This raised the possibility of bias introduced into the study by the subjects' selection on the basis of a claim for compensation. To clarify the effects of age, exposure, and radiographic abnormalities on the mortality of subjects who have been exposed to asbestos but have not necessarily sought compensation we have taken a random sample of the entire 
workforce of Wittenoom between 1943 and 1966 and examined their survival experience in relation to these variables.

\section{Subjects}

There were about 7000 workers employed in the crocidolite industry at Wittenoom Gorge between 1943 until 1966. The employment records of the Australian Blue Asbestos Company (ABA) have been retained and form the basis of a continuing follow up study of morbidity and mortality in the workforce that has been conducted since $1975 .{ }^{31112}$ This study has provided information on vital status and cause of death of most of the employees, about $70 \%$ of whom are known to be dead or alive and living in Australia. Quantitative estimates of exposure to crocidolite of all subjects in the industry have been made possible by the existence of records of fibre counting in the industry. ${ }^{13}$ Compulsory chest $x$ ray films of workers entering the mining industry and periodically while they remain in it, an active tuberculosis control programme in the State in the past, doctors' referrals or voluntary presentation for free chest radiographs, and a policy of indefinite preservation of all films have led to an invaluable collection of serial chest $x$ ray films at the Perth Chest Clinic.

A one in six random sample of all male Wittenoom workers (including those who had sought compensation) was selected and attempts were made to obtain all plain chest radiographs on them held in the Perth teaching hospitals or the Perth Chest Clinic. A total of 1106 men was selected. Radiographs were retrieved for 921 men and of these 740 had radiographs taken at or after commencing employment at Wittenoom. Four hundred and sixty seven had $x$ ray films taken more than six months after they had started work at Wittenoom.

\section{Methods}

All radiographs were classified independently by two observers (A W M and J J G) according to the 1980 International Labour Office (ILO) classification of radiographs for pneumoconiosis. ${ }^{14}$

The duration and place of work at Wittenoom for each subject have been documented. ${ }^{3}$

The concentrations of airborne respirable fibres greater than $5 \mu$ in length in various workplaces were measured in $1966 . .^{13}$ This information permitted an estimate of the cumulative exposure for each subject in fibres/ml-years ( $\mathrm{f} /$ ml-years).$^{3}{ }^{12}$

Demographic and basic exposure data were obtained from employment records supplemented, when incomplete, by records of the Perth Chest Clinic, which took compulsory pre-employment and periodic subsequent chest $x$ ray film examinations of the men (both miners and millers), and by records of the Western Australian Mineworkers
Relief Fund, a compulsory benevolent fund to which the company paid monthly subscriptions for each employee. These data included date of birth, nationality, and date and occupation at the beginning and date of end of each period of employment. Vital status and date and cause of death were determined as part of the mortality study of the total cohort up to the end of $1986 . .^{12}$

Five separate case-control analyses were performed. The outcomes in the five sets of cases were: (1) all causes, (2) malignant mesothelioma, (3) cancer of the trachea, bronchus, and lung, (4) asbestosis, and (5) all causes excluding cancer and asbestosis. Controls were chosen from all men of exactly the same age who were not known to have died before the date of death of the index case. Up to 20 controls, if possible, were randomly chosen. If there were fewer than 20 men eligible to be selected then all eligible men were chosen as controls.

Conditional logistic regression analyses ${ }^{15}$ were used to model the relative risk of death from each of the above causes with the computer program Egret. ${ }^{16}$ The covariates considered were (1) log (cumulative exposure +1 ), (2) years since first employed, and (3) level of radiographic abnormality, either in minor ILO categories for profusion of small opacities or in categories of thickness and extent for pleural thickening.

Scores on $x$ ray films were grouped according to time before the death of the case. Thus each person's $x$ ray film history was coded as: presence or absence of an $x$ ray film and their latest level of profusion and thickening in the periods before the death of the case of (1) less than or equal to one year (any signs in this period were considered to be early presence of disease rather than true precursors of disease and were ignored), (2) two to five years ago, (3) six to 10 years ago, (4) 11 to 20 years ago, (5) 21 to 30 years ago, and (6) 31 or more years ago. Analyses were done separately for each period and were restricted to those subjects who had had an $x$ ray film during that period. The effects of the radiographic scores were examined alone, and then after adjustment for exposure.

As an added comparison with the previous study on compensated subjects alone, ${ }^{7}$ the effect of exposure on the level of radiographic abnormality on the final film for each person was examined with multiple regression. This analysis was restricted to the 467 men with $x$ ray films taken more than six months after commencing employment at Wittenoom.

\section{Results}

Out of a total of 193 deaths among the 1106 selected subjects there were 12 from mesothelioma, 19 from lung cancer, 24 from other cancers, and nine 
Table 1 Causes of death in 1106 men

\begin{tabular}{lc}
\hline Cause & $\begin{array}{c}\text { No of } \\
\text { deaths }\end{array}$ \\
\hline Malignant mesothelioma & 12 \\
Lung cancer & 19 \\
Stomach cancer & 2 \\
Other cancer & 22 \\
Pneumoconiosis & 9 \\
All other causes & 129 \\
\hline
\end{tabular}

from asbestosis (table 1). By comparison with the total cohort of Wittenoom workers, ${ }^{12}$ there were fewer deaths than expected (on a proportional basis) from every cause examined, although exposure to asbestos was similar (table 2).

After adjustment for cumulative exposure, there was a significant effect of $x$ ray film profusion on mortality from all causes (table 3 ). The further back in time the $x$ ray films were taken, the lesser the effect, which was not statistically significant more than 20 years previously. A similar effect was found for pleural thickening but this only became non-significant more than 30 years previously.

On examination of the effects of the radiographic variables on death from separate causes it was clear that the effect of profusion was largely on mortality from mesothelioma and asbestosis whereas pleural thickening seemed to be a risk factor for death from ischaemic heart disease, which formed the largest proportion of deaths from other causes (table 3). There was no significant effect of either exposure to asbestos or radiographic abnormality on mortality from lung cancer. There was an additional logarithmic decrease in the mortality from other causes with time from first exposure.

Figures 1-3 show comparative sizes of the different estimated effects of both radiographic signs and exposure to asbestos on the different causes of death. The strongest effects of both factors were on deaths from asbestosis and mesothelioma.

Age at first exposure, time since first exposure, and the $\log$ of cumulative exposure were all significant predictors of both radiographic profusion of small opacities and diffuse pleural thickening on the subjects' final $x$ ray films (table 4 ). The coefficients for time from first exposure for both types of abnormality were more than double the respective age at

Table 2 Exposure to asbestos (geometric means) and cause of death

\begin{tabular}{llll}
\hline & $\begin{array}{l}\text { Cumulative } \\
\text { (f/ml-years) }\end{array}$ & $\begin{array}{l}\text { Intensity } \\
(\mathrm{f} / \mathrm{ml})\end{array}$ & $\begin{array}{l}\text { Duration } \\
\text { (days) }\end{array}$ \\
\hline Lung cancer & 11 & 17 & 223 \\
Mesothelioma & 44 & 24 & 660 \\
Asbestosis & 84 & 30 & 1032 \\
Remainder & 7 & 14 & 164 \\
Controls & 6 & 13 & 153 \\
\hline
\end{tabular}

* Mean of the mean of all sets of controls.
Table 3 Effect of radiographic abnormality (two to five years earlier) and exposure on mortality from various causes (nonsignificant $(p>0.3)$ variables omitted)

\begin{tabular}{|c|c|c|}
\hline & $\begin{array}{l}\text { Relative } \\
\text { Risk (95\% CI) }\end{array}$ & p Value* \\
\hline \multicolumn{3}{|l|}{ All causes: } \\
\hline Profusion (/minor ILO category) & $1 \cdot 3(1 \cdot 1-1 \cdot 5)$ & 0.006 \\
\hline Pleural thickening & & \\
\hline (/25\% increase) & $1 \cdot 3(1 \cdot 1-1 \cdot 5)$ & 0.002 \\
\hline $\begin{array}{l}\text { Log (cumulative exposure; } \\
\text { f/ml-years) }\end{array}$ & $1 \cdot 2(1 \cdot 1-1 \cdot 3)$ & $<0.001$ \\
\hline Log (time from first exposure; y) & $0.5(0.4-0.6)$ & 0.004 \\
\hline \multicolumn{3}{|c|}{ Malignant mesothelioma: } \\
\hline Profusion & $1.9(1.3-2.9)$ & 0.002 \\
\hline Log (cumulative exposure) & $2.5(1.6-4 \cdot 0)$ & $<0.001$ \\
\hline $\begin{array}{l}\text { Lung cancer: } \\
\text { Log (cumulative exposure) }\end{array}$ & & \\
\hline $\begin{array}{l}\text { Log (cumulative exposure) } \\
\text { Asbestosis: }\end{array}$ & $1.2(0.9-1 \cdot 6)$ & $0 \cdot 12$ \\
\hline $\begin{array}{l}\text { Profusion } \\
\text { Log (cumulative exposure) }\end{array}$ & $\begin{array}{l}1.6(1 \cdot 1-2 \cdot 3) \\
4 \cdot 0(1 \cdot 8-8 \cdot 8)\end{array}$ & $\begin{array}{l}0.02 \\
<0.001\end{array}$ \\
\hline \multicolumn{3}{|l|}{ Other causes: } \\
\hline Pleural thickening & $1 \cdot 5(1 \cdot 3-1 \cdot 8)$ & $<0.001$ \\
\hline Log (time from first exposure) & $0.5(0.3-0.7)$ & 0.002 \\
\hline
\end{tabular}

${ }^{\star} \mathrm{p}$ Value for removal from full model.

first exposure coefficients. Replacing the two time terms by age at $x$ ray film (the sum of age at first exposure and time from first exposure) resulted in a significantly worse fit to the data.

\section{Discussion}

This study has shown that in a sample of randomly selected subjects with exposure to crocidolite at Wittenoom, after adjusting for the effects of age, mortality from all causes was determined by the level of both pleural and parenchymal radiographic abnormality, the cumulative exposure to asbestos, and the time from first starting work. Both types of radiographic abnormality had their maximum effect on mortality between two and five years after the $x$ ray film. Also, the degree of both types of abnormality was also dependent on the cumulative exposure to asbestos, age at first exposure, and time

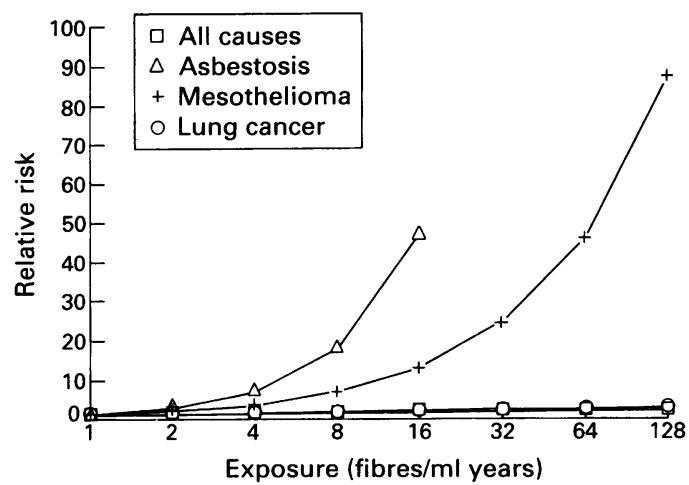

Figure 1 Estimated change in relative risk of death from asbestosis, mesothelioma, lung cancer, and all causes for levels of cumulative exposure to crocidolite. 


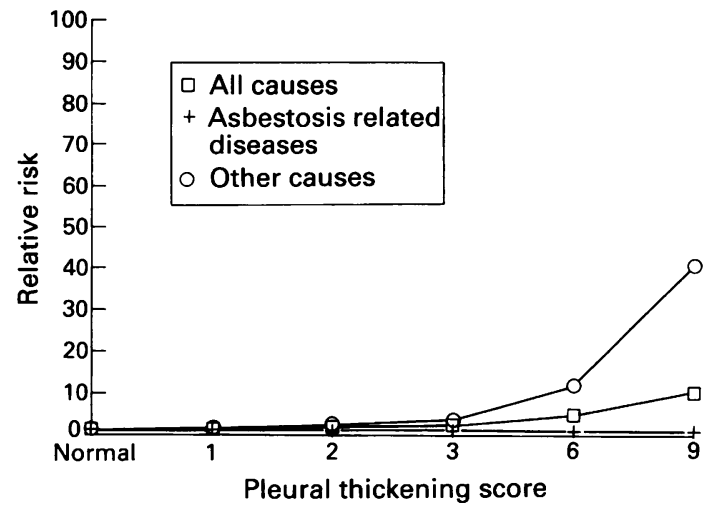

Figure 2 Estimated change in relative risk of death from asbestosis, mesothelioma, lung cancer, and all causes for levels of ILO profusion of small opacities.

from first exposure. The difference in the regression coefficients of age at first exposure and time from first exposure associated with both abnormalities showed that the effect of time from first exposure was unlikely to be just an effect of age.

Exposure to asbestos had a strong effect on mortality from mesothelioma and asbestosis even after adjustment for degree of radiographic profusion and in turn, mortality from malignant mesothelioma and asbestosis were related to profusion of small opacities in the two to five years before death.

There was no significant effect of any measure of exposure to asbestos on mortality from lung cancer; neither was there a significant effect of any radiographic measure of pleural or parenchymal fibrosis. The relative risk of mortality from lung cancer for $\log$ (cumulative exposure) of 1.2 was not, however, greatly different from the 1.4 found

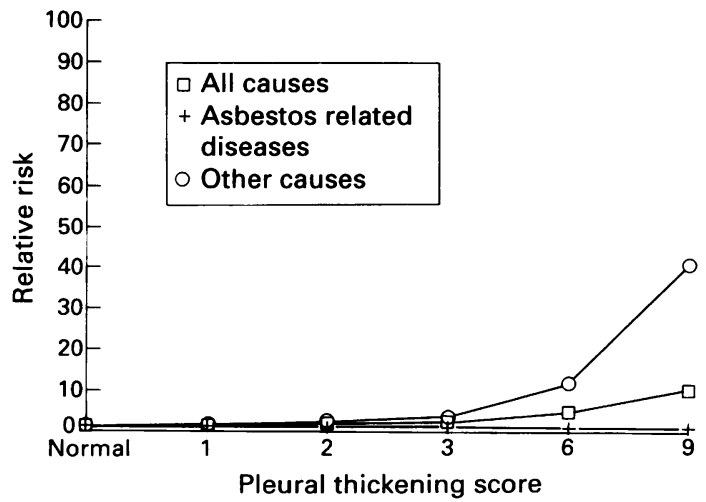

Figure 3 Estimated change in relative risk of death from all causes, asbestos related diseases (mesothelioma, asbestosis, and lung cancer), and other causes for levels of categories of thickness and extent of diffuse pleural thickening.
Table 4 Effect of exposure to asbestos on abnormalities on final $x$ ray films

\begin{tabular}{llll}
\hline & $b^{*}$ & $(95 \% C I)$ & $r^{2}$ \\
\hline Level of profusion: & & & \\
$\quad$ Log(cumulative exposure) & 0.13 & $(0.05-0.21)$ & \\
Time since starting work(y) & 0.04 & $(0.03-0.05)$ & 0.10 \\
Age at starting work & 0.017 & $(0.002-0.033)$ & \\
Level of thickening: & & & \\
Log(cumulative exposure) & 0.10 & $(0.02-0.18)$ & \\
Time since starting work(y) & 0.07 & $(0.06-0.08)$ & 0.19 \\
Age at starting work & 0.016 & $(0.000-0.032)$ & \\
\hline
\end{tabular}

*Increase in minor ILO category for profusion and in category of thickness and extent for pleural thickening per unit increase in exposure variable.

in a more powerful study among Wittenoom workers with known smoking habits. ${ }^{17}$ It has been estimated that smoking caused $71 \%$ of the 132 deaths from lung cancer among men in the whole Wittenoom cohort. ${ }^{18}$ Given the small numbers of lung cancers in this random sample, this study had little power to detect an effect of either exposure or radiographic abnormality and does not therefore contribute to understanding the relations between exposure to asbestos, asbestosis, and lung cancer.

Pleural thickening had no effect on mortality from diseases related to asbestos but seemed to influence deaths from other causes (particularly ischaemic heart disease). This finding suggests a chance association although it is now accepted that pleural thickening is not totally benign ${ }^{19}$ and poor lung function has often been associated with mortality from cardiovascular disease. ${ }^{20}$ The significant reduction in mortality from causes other than those related to asbestos with time from first exposure was probably due to the occurrence of undetected deaths, which has been shown to be related to age in other analyses. ${ }^{21}$

The results of this study differ from those found in a previous study in subjects from Wittenoom who were selected because they had applied for pneumoconiosis compensation. ${ }^{7}$ In compensated men whose exposures were all relatively high, the degree of exposure had no independent effect on survival whereas the effect of exposure on profusion level was more than twice that found in this random sample. Since the first study was completed all subjects have had their estimated airborne exposures re-evaluated ${ }^{3}$ and this could contribute to these differences especially as in the previous study there was also a large and significant effect of working in the mill on mortality from asbestosis and all causes that was not present in this study.

The significant effect of exposure to asbestos on pleural thickening also contrasts with that found previously in a study of heavily exposed men applying for compensation. ${ }^{22}$ In that study no exposure related variable had any effect on incidence or progression of pleural thickening except in the period 
five to 15 years after first exposure. This could again be due to the greater range of exposures over the whole cohort.

This study shows that the degree of profusion of small irregular opacities on plain chest $x$ ray film has an independent effect on mortality from malignant mesothelioma and asbestosis even after allowing for the effects of age, degree of exposure, and time since exposure.

We are grateful to the staff at the Perth Chest Clinic and the Sir Charles Gairdner Hospital for assisting in locating radiographs and to Miss Elizabeth Bingle for her secretarial assistance.

Requests for reprints to: Nicholas de Klerk, Department of Public Health, University of Western Australia, Nedlands, 6009, Western Australia.

1 Selikoff IJ, Hammond EC, Seidman H. Mortality experience of insulation workers in the United States and Canada, 1943-1976. Ann NY Acad Sci 1979;330:91-116.

2 Doll R, Peto J. Effects on health of exposure to asbestos. Health and Safety Commission, London: HMSO, 1985.

3 Armstrong BK, de Klerk NH, Musk AW, Hobbs MST. Mortality in miners and millers of crocidolite in Western Australia. Brf Ind Med 1988;45:5-13.

4 de Klerk NH, Armstrong BK, Musk AW, Hobbs MST. Cancer mortality in relation to measures of occupational exposure to crocidolite at Wittenoom Gorge in Western Australia. Br f Ind Med 1989;46:529-36.

5 Berry G, Gilson JC, Holmes S, Lewinsohn H, Roach S. Asbestosis: a study of dose response relationships in an asbestos textile factory. Br F Ind Med 1979;36:98-112.

6 de Klerk NH, Armstrong BK, Musk AW, Hobbs MST. Predictions of future asbestos-related disease cases among former miners and millers of crocidolite in Western Australia. Med f Aust 1989;151:616-20.

7 Cookson WOC, Musk AW, Glancy JJ, de Klerk NH, Yin R, Mele $R$, et al. Compensation, radiographic changes and survival in applicants for asbestosis compensation. $\mathrm{Br} F$ Ind Med 1985;42:461-8.

8 Liddell FDK, McDonald JC. Radiological findings as predic- tors of mortality in Quebec asbestos workers. $\mathrm{Br} \mathcal{F}$ Ind Med 1980;37:257-67.

9 Hughes JM, Weill $\mathrm{H}$. Asbestosis as a precursor of asbestos related lung cancer: results of a prospective mortality study. Br F Ind Med 1992;48:229-33.

10 Sluis-Cremer GK, Bezuidenhout BN. Relation between asbestosis and bronchial cancer in amphibole asbestos miners. Br F Ind Med 1989;46:537-40.

11 Hobbs MST, Woodward SD, Murphy B, Musk AW, Elder JE. The incidence of pneumoconiosis, mesothelioma and other respiratory cancer in men engaged in mining and milling crocidolite in Western Australia. In: Wagner JC, ed. Biological effects of mineral fibres. Lyon: International Agency for Research on Cancer, 1980:615-25. (Sci publ No 30.)

12 de Klerk NH, Musk AW, Armstrong BK, Hobbs MST. Diseases in miners and millers of crocidolite from Wittenoom, Western Australia: a further follow-up to December 1986. Ann Occup Hygi (in press).

13 Major G. Asbestos dust exposure. In: Major G, ed. Proceedings of the first Australian Pneumoconiosis Conference, Sydney, 1968. Sydney: Joint Coal Board, 1968:467-74.

14 International Labour Office. Guidelines for the use of ILO international classification of radiographs on pneumoconiosis. Geneva: ILO, 1980 (Occupational Safety and Health Series, No 22).

15 Breslow NE, Lubin JH, Marek P, Langholz B. Multiplicative models and cohort analysis. Fournal of the American Statistical Association 1983;78:1-12.

16 SERC. Program EGRET. Seattle, Washington: SERC, 1987.

17 de Klerk NH, Armstrong BK, Musk AW, Hobbs MST. Smoking, exposure to crocidolite, and the incidence of lung cancer and asbestosis. Br F Ind Med 1991;48:412-7.

18 de Klerk NH, Musk AW, Eccles JL, Hobbs MST. Contributions of asbestos, alcohol and smoking to deaths in subjects occupationally exposed to crocidolite at Wittenoom gorge. Proceedings of the 8th international conference on occupational lung diseases (in press).

19 Lilis R, Miller A, Godbold J, Chan E, Selikoff IJ. Radiographic abnormalities in asbestos insulators: effects of duration from onset of exposure and smoking. Relationships of dyspnea with parenchymal and pleural fibrosis. Am $\mathcal{f}$ Ind Med 1991;20:1-15.

20 Visalpattanasin P, Armstrong BK, de Klerk NH, English DR, for the Busselton Population Studies Group. Mortality in Busselton, Western Australia, 1966 to 1983 Perth; The University of Western Australia, 1988.

21 Berry G. Prediction of mesothelioma, lung cancer, and asbestosis in former Wittenoom asbestos workers. $\mathrm{Br} \mathcal{F}$ Ind Med 1991;48:793-802.

22 de Klerk NH, Cookson WOC, Musk AW, Armstrong BK, Glancy JJ. Natural history of pleural thickening after exposure to crocidolite. Br $\mathcal{F}$ Ind Med 1989;46:461-67.

Accepted 21 December 1992 
Table Comparison of relative risk ( $R R)$, risk odds ratio $(O R)$, incidence rate ratio (IRR), prevalence odds ratio (POR) and prevalence ratio (PR). An index (A or $B$ ) refers to a specific subpopulation. The hypothetical populations are assumed to fulfil necessary stationarity assumptions.

\begin{tabular}{|c|c|c|c|c|c|c|c|c|c|c|}
\hline \multirow[b]{2}{*}{$R_{A}^{*}$} & \multirow[b]{2}{*}{$R_{B} \dagger$} & \multirow[b]{2}{*}{$R R$} & \multirow[b]{2}{*}{$O R$} & \multirow[b]{2}{*}{$I R R$} & \multicolumn{2}{|c|}{$D_{A} \ddagger=D_{B} \S=1$} & \multicolumn{2}{|c|}{$D_{A}=D_{B}=4$} & \multicolumn{2}{|c|}{$D_{A}=4 ; D_{B}=1$} \\
\hline & & & & & $P O R$ & $P R$ & $P O R$ & $P R$ & $P O R$ & $P R$ \\
\hline $\begin{array}{l}0.60 \\
0.60 \\
0.60 \\
0.40 \\
0.20 \\
0.20\end{array}$ & $\begin{array}{l}0.50 \\
0.30 \\
0 \cdot 10 \\
0 \cdot 10 \\
0.10 \\
0.05\end{array}$ & $\begin{array}{l}1 \cdot 20 \\
2.00 \\
6.00 \\
4.00 \\
2.00 \\
4.00\end{array}$ & $\begin{array}{c}1.50 \\
3.50 \\
13.5 \\
6.00 \\
2.25 \\
4.75\end{array}$ & $\begin{array}{l}1 \cdot 32 \\
2.57 \\
8 \cdot 70 \\
4 \cdot 85 \\
2 \cdot 12 \\
4.35\end{array}$ & $\begin{array}{l}1 \cdot 32 \\
2 \cdot 57 \\
8 \cdot 70 \\
4 \cdot 85 \\
2 \cdot 12 \\
4 \cdot 35\end{array}$ & $\begin{array}{l}1 \cdot 17 \\
1.82 \\
5.02 \\
3.55 \\
1.92 \\
3.73\end{array}$ & $\begin{array}{l}1 \cdot 32 \\
2 \cdot 57 \\
8 \cdot 70 \\
4 \cdot 85 \\
2 \cdot 12 \\
4 \cdot 35\end{array}$ & $\begin{array}{l}1.07 \\
1.34 \\
2.65 \\
2.26 \\
1.59 \\
2.77\end{array}$ & $\begin{array}{c}5 \cdot 29 \\
10 \cdot 3 \\
34 \cdot 8 \\
19 \cdot 4 \\
8 \cdot 48 \\
17 \cdot 4\end{array}$ & $\begin{array}{l}1.92 \\
2.99 \\
8.24 \\
7.04 \\
4.96 \\
9.65\end{array}$ \\
\hline
\end{tabular}

${ }^{\star} R_{A}=$ Risk of developing illness in subpopulation $A$ during 1 time unit.

$+R_{B}=$ Risk of developing illness in subpopulation $B$ during 1 time unit.

$\ddagger D_{A}=$ Mean duration of illness in subpopulation $A$ (time units).

$\delta D_{B}=$ Mean duration of illness in subpopulation $A$ (time units).

their notation, prevalence rate ratio (PRR) is used instead of prevalence ratio (PR), which seems confusing, as prevalence and rate are different concepts. The fundamental flaw in their argumentation, however, is that they place, in some respects, cross sectional studies on an equality with longitudinal studies by considering a PR as a relative risk and a POR as a risk odds ratio when comparing the effect measures; as is seen in the table, this is certainly not true. Contrary to their conclusion, by estimating the ratio of the mean durations, $D_{A} / D_{B}$, a POR can easily be converted into an incidence rate ratio (under certain stationarity assumptions), ${ }^{1}$ whereas a relation between the $P R$ and some aetiologically understandable effect measure may be more difficult to see through.

Moreover, Lee and Chia's description is imperfect in another respect: the reader is left with the impression that the POR is the only effect measure possible to estimate under a logistic regression model; if a PR is desired instead, it can always be obtained from the estimated probabilities of study illness for different covariate patterns, based on the model. ${ }^{3}$

It should be stressed that restricted stationarity assumptions underlie the derivation of the mentioned relations between prevalence, incidence, and duration and hence limit the applicability of these known relations. As far as I know, there are no empirical studies that show to what extent departures from these assumptions may influence the effect estimates. In practice, the underlying mechanisms that affect the outcome of a cross sectional study are complex. Hopefully, recent theoretical work $^{4}{ }^{5}$ will somehow improve our ability to analyse and interpret data from cross sectional studies.

ULF STRÖMBERG

Department of Occupational and Environmental Medicine,

University Hospital, S-221 85 Lund, Sweden

1 Feeman J, Hutchison GB. Prevalence, incidence and duration. Am $\mathcal{F}$ Epidemiol 1980 112:707-23.

2 Greenland S, Thomas DC. On the need of the rare disease assumption in case-control studies. Am ₹ Epidemiol 1982;116:547-53.

3 Hosmer DW, Lemeshow S. Applied logistic regression. New York: Wiley, 1989.

4 Keiding N. Age-specific incidence and prevalence: A statistical perspective. Fournal of the Royal Soc A 1991;154:371-412.

5 Alho JM. On prevalence, incidence, and dure tion in general stable populations. Biometrics tion in general st.

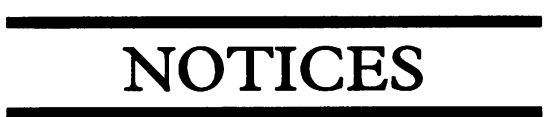

Reminder

Symposium on health hazards of glycol ethers. 19-21 April 1994, Abbay de Port-à Mousson, Nancy, France

(More details appear in $\mathrm{Br} \mathcal{f}$ Ind $\mathrm{Med}$ 1993;50(November):1056) For further information contact the Symposium Secretariat, International Symposium on Health Hazards of Glycol Ethers, INRS, Avenue de Bourgogne BP 27 F54 501 Vandoeuvre Cédex France. Tel (33) 8350 20 27, Fax (33) 83502096.

Fourth International Conference on Education and Training in Occupational Health, 24-28 April 1994, Amsterdam, The Netherlands.

The conference is organised by the Amsterdam School of Occupational Medicine, Corvu and will take place in the buildings of the Universiteit van Amsterdam. It aims at those involved in teaching professionals in the field of occupational health, safety, and wellbeing. The scientific programme consists of oral presentations, workshops, poster sessions, and, as a new element, demonstration lessons. I is built up along two lines. Firstly, the establishment, performance, and evaluation of an education and training programme. Secondly, the establishment, performance, and evaluation of an occupational health and safety programme in a company. During the whole conference there will be an information market and a sponsor market. The fee is DFL 820 (members of ICOH may register for DFL 780).

For more information, contact the Conference Office, Universiteit van Amsterdam, PO Box 192681000 GG Amsterdam, The Netherlands, fax +31-205252771 or email congres @ bdu.uva.nl.

\section{NEW BOOK ANNOUNCE- MENTS}

Health promotion in the Workplace: Alcohol and Drug Abuse Report of a WHO Expert Committee Technical Report Series No 833. 1993, v +34 pages (available in English; French and Spanish in preparation). ISBN 9241208333

Sw fr 7.-/US $\$ 6 \cdot 30$.

In developing countries: Sw fr $\mathbf{4} \cdot 90$.

Order No 1100833

Electromagnetic Fields (300 Hz-300 GHz)

Environmental Health Criteria No 137.

1993, 282 pages (English, with summaries in French and Spanish).

ISBN 9241571373

Sw fr 34.-/US $\$ 30 \cdot 60$.

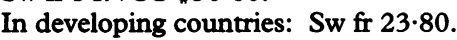

Order No 1160137.

1,3-Dichloropropene,

1,2-Dichloropropane and Mixtures Environmental Health Criteria No 146.

1993, 261 pages (English, with summaries in French and Spanish).

ISBN 9241571462

Sw fr 31.-/US $\$ 27.90$.

In developing countries: Sw fr $21 \cdot 70$.

Order No 1160146.

\section{Methyl Parathion}

Environmental Health Criteria No 145.

1993, 244 pages (English, with summaries in French and Spanish).

ISBN 9241571454

Sw fr 28 -/US $\$ 25 \cdot 20$

In developing countries: Sw fr 19.60. Order No 1160145.

\section{Correction}

Radiographic abnormalities and mortality in subjects with exposure to crocidolite (1993;50:902-906).

During printing fig 2 ( $p$ 905) was inadvertently changed. The correct fig 2 is given here:

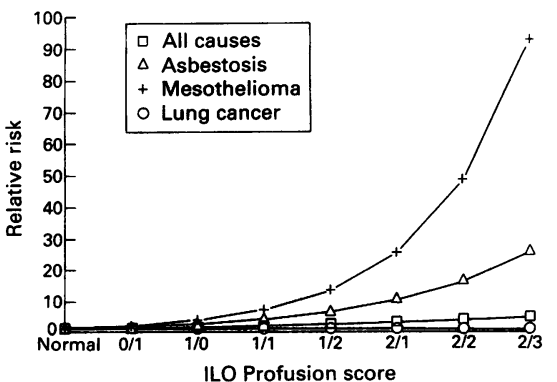

